\title{
Educação popular e nutrição social: considerações teóricas sobre um diálogo possível
}

Pedro José Santos Carneiro Cruz ${ }^{(a)}$ José Francisco de Melo Neto ${ }^{(b)}$

Cruz PJSC, Melo Neto JF. Popular education and social nutrition: theoretical considerations on a possible dialogue. Interface (Botucatu). 2014;18 Supl 2:1365-1376.

In the health sector, the Popular Education has historically unveiled relevant theoretical and methodological perspectives in the search for new horizons for education of professionals, among which also include nutritionists. Pathways have been designed for a work in social nutrition committed to the concepts of Health Promotion and Food Safety and Nutrition, which add critical dimensions to the Social Nutrition, translated by its perception as committed to the role of nutrition science in popular communities and the nutritionist intervention in these spaces. Aiming to contribute to the improvement of the theoretical bases involved in this process, this essay aims to systematize the current challenges, possibilities and shortcomings of the encounter between Popular Education and Social Nutrition, with emphasis on their accomplishments in the scenarios of Family Health, and movements in around the Human Right to Adequate Food and Healthy in Brazil.

Keywords: Health Education; Nutrition Programs and Policies; Nutrition, Public Health; Food and Nutrition Education.
No setor saúde, a Educação Popular tem desvelado historicamente perspectivas teóricas e metodológicas relevantes na busca por novos horizontes para formação de profissionais, dentre os quais também se incluem os nutricionistas. Caminhos vêm sendo delineados para uma atuação comprometida com os conceitos da Promoção da Saúde e da Segurança Alimentar e Nutricional, os quais agregam dimensões críticas à Nutrição Social, traduzidas pela percepção compromissada quanto ao papel da ciência da nutrição em comunidades populares e da intervenção do nutricionista nestes espaços. Tendo como objetivo contribuir no aprimoramento das bases teóricas intervenientes neste processo, o presente ensaio pretende sistematizar os atuais desafios, possibilidades e lacunas do encontro entre Educação Popular e Nutrição Social, com ênfase para suas realizações nos cenários da Saúde da Família, e dos movimentos em torno do Direito Humano à Alimentação Adequada e Saudável no Brasil.

Palavras-chave: Educação em Saúde. Programas e Políticas de Nutrição e Alimentação. Nutrição em Saúde Pública. Educação Alimentar e Nutricional.

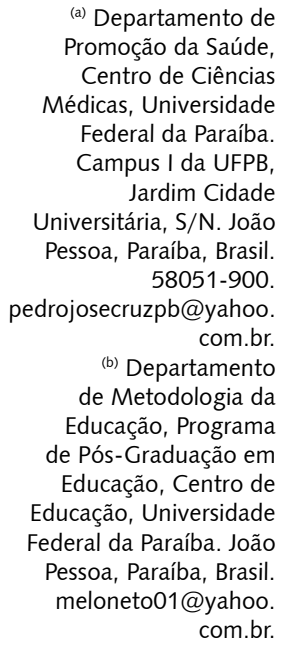

(a) Departamento de Promoção da Saúde, Centro de Ciências Médicas, Universidade Federal da Paraíba. Campus I da UFPB, Jardim Cidade Universitária, S/N. João Pessoa, Paraíba, Brasil. 58051-900. pedrojosecruzpb@yahoo. com.br. (b) Departamento de Metodologia da Educação, Programa de Pós-Graduação em Educação, Centro de Educação, Universidade Federal da Paraíba. João Pessoa, Paraíba, Brasil. meloneto01@yahoo. com.br. 


\section{Introdução}

Nos últimos anos, diversos fatores vêm demandando mudanças na atuação profissional e na formação universitária de nutricionistas, seja em seus princípios éticos, nos aspectos políticos ou nas questões quanto às formas de atuar e participar, especialmente em contextos permeados pela exclusão social ${ }^{1,2,3}$. Contudo, as experiências de inserção de nutricionistas neste cenário passaram a revelar um anacronismo da formação tradicional diante dos desafios impostos pelas situações sociais cotidianamente vivenciadas pelo público protagonista deste nível de atenção ${ }^{4,5,6,7}$. Como demonstram diferentes estudos ${ }^{5,8,9}$, problemas sociais como exclusão, fome, miséria, entre outros, demandavam modos de atuação distintos dos tradicionais, com ênfase na sensibilidade do profissional para compreender o problema da fome, da pobreza e seus condicionantes de forma ampliada (através da complexidade e da compreensão estrutural dos problemas sociais), crítica e humanizada, envolvendo também uma ação com ênfase social, cultural e educativa.

Nesse contexto, a Educação Popular vem constituindo um significativo componente inspirador para a formação e a atuação de nutricionistas no campo da Nutrição Social, especialmente no contexto da Estratégia Saúde da Família (ESF) e das ações de promoção da Segurança Alimentar e Nutricional (SAN). Conforme ressaltam Cruz, Pereira e Vasconcelos ${ }^{10}$, enquanto teoria da Educação ${ }^{11,12,13}$, a Educação Popular traz um escopo de inspirações teóricas e tecnologias sociais relevantes capazes de oportunizar o desenvolvimento de profissionais com postura ética comprometida com ações de Promoção da Saúde e da Alimentação Saudável em caráter ampliado, orientadas, sobretudo pelo conceito de Segurança Alimentar e Nutricional (SAN), o qual agrega dimensões críticas, sociais e políticas à compreensão do papel da ciência da nutrição em comunidades populares e da intervenção do nutricionista nestes espaços ${ }^{14}$.

Todavia, percebe-se na literatura sobre Nutrição Social uma escassez de referências que coloquem estas iniciativas em análise crítica e promovam um aprofundamento teórico sobre este diálogo entre Educação Popular e Nutrição Social, o que revela, nestes campos, um desafio a ser enfrentado. Nesse sentido, o presente ensaio possui como objetivo central contribuir com este debate, estabelecendo algumas reflexões comprometidas com a expansão e qualificação crítica do debate em torno dos atuais desafios, possibilidades e lacunas do encontro entre as perspectivas teóricas da Educação Popular e da Nutrição Social.

Para tanto, iremos, em primeiro lugar, destacar breves entendimentos teóricos sobre estes dois conceitos, para depois situar encontros significativos decorridos entre as práticas de Educação Popular e as práticas de Nutrição Social. Em seguida, situaremos as atuais aproximações teóricas entre estes campos, ao tempo em que revelaremos também suas lacunas. Finalmente, apostando no arcabouço epistemológico da Educação Popular e nos avanços históricos de compromisso social da ciência da Nutrição, deveremos colocar em debate possibilidades para um maior aprofundamento acerca deste encontro, confluindo na perspectiva de refletir criticamente a prática da Educação Alimentar e Nutricional (EAN) como possibilidade concreta de concretizar processos emancipatórios na atuação da Nutrição Social em contextos de exclusão social.

\section{Desenvolvimento}

\section{Considerações metodológicas}

Este artigo resulta de uma pesquisa original teórica, desenvolvida por ocasião de estudos provenientes da construção de tese de Doutoramento em Educação do autor principal, sob orientação do co-autor, construída na perspectiva qualitativa ${ }^{15}$, a partir de inquietações e questões emergidas aos pesquisadores no seio de suas experiências no campo das práticas de Extensão Universitária em Educação Popular no setor saúde. Para desenvolvê-la, procedemos com pesquisa bibliográfica ${ }^{15,16}$. Segundo Gil16, a pesquisa bibliográfica é desenvolvida com base em material já elaborado, constituído 
principalmente de livros e artigos científicos. Sua finalidade é colocar o pesquisador em contato com o que já se produziu e se registrou a respeito do tema de pesquisa.

Tal técnica de pesquisa foi utilizada de modo a podermos considerar documentos oficiais de políticas públicas de saúde, proteção social, dentre outras, inseridas no campo da Nutrição Social. Também consideramos reflexões teóricas provindas de pesquisas teóricas e sistematizações de experiências em práticas de Educação Alimentar e Nutricional. Estas obras encontram-se citadas ao longo do artigo, conforme as normas da ABNT, e sua escolha deu-se de forma intencional, com critério de incluir aquelas que tivessem conteúdo articulado com os propósitos específicos deste ensaio.

\section{Educação Popular e Nutrição Social: perspectivas teóricas}

A Educação Popular nasce no início no século XX em meio ao cenário diverso das perspectivas críticas de pensar o fenômeno da Educação na América Latina e passa a ser melhor sistematizada, compreendida e aperfeiçoada a partir da década de 1950, a partir de sua processual realização nos processos de educação de jovens e adultos, bem como nos movimentos de cultura popular ${ }^{13,17}$.

Esta perspectiva crítica foi construída a partir dos fundamentos teóricos erguidos pela obra de Marx e Engels ${ }^{18}$, a qual conferiu bases filosóficas e teóricas significativas para se pensar a produção do conhecimento numa perspectiva dialética que tem como ponto de partida, necessariamente, o mundo concreto e suas contradições. Estando radicalmente inserida nas lutas contra opressão na América Latina e nos movimentos de cultura popular, aos poucos, a Educação Popular foi ganhando espaço em outros campos do conhecimento e em diferentes áreas profissionais, na medida em que subsidiava bases para se questionar a aplicação tradicional das ciências, reivindicando processos educativos que garantissem uma atuação da ciência comprometida com a geração de processos emancipatórios nos contextos de exclusão social onde se insere. Nesse sentido, a Educação Popular apresenta-se ainda nos dias de hoje como eminentemente necessária, constituindo um marco teórico e uma teoria do conhecimento de relevância singular para trabalhos sociais e ação de políticas públicas com perspectiva educativa libertária, democrática e participativa ${ }^{19}$. Para Calado ${ }^{20}$, significa:

[...] um processo formativo, protagonizado pela Classe Trabalhadora e seus aliados, continuamente alimentado pela utopia, em permanente construção de uma sociedade economicamente justa, socialmente solidária, politicamente igualitária, culturalmente diversa, dentro de um processo coerentemente marcado por práticas, procedimentos, dinâmicas, posturas correspondentes ao mesmo horizonte.

Cumpre destacar que a Educação Popular não é a única perspectiva teórica para uma educação libertadora. No entendimento de Paludo ${ }^{21}$, ela faz parte do chamado Campo Democrático Popular (CDP), no qual atuam também perspectivas teóricas e filosóficas de relevância na educação como: a Teologia da Libertação; o Novo Sindicalismo; os Centros de Educação e Promoção Popular; o pensamento pedagógico socialista, cuja base está no materialismo histórico e materialismo dialético de autores como Marx, Lênin e Gramsci; as múltiplas experiências de movimentos sociais e populares ocorridas em toda a América Latina; além das experiências socialistas do Leste Europeu e aquelas de países latino-americanos como Nicarágua, Chile e Cuba.

Neste novo século, a Educação Popular permanece em diálogo com estas diferentes perspectivas, mas mantém sua importância singular no contexto vivenciado pela sociedade, pois ainda está em voga uma educação hegemônica excludente, autoritária, direcionada a reafirmar a sociedade como aí está.

Por sua vez, especialmente desde a década de 1930, a Nutrição Social vem se desenvolvendo no contexto das perspectivas de pensar e concretizar a ciência da Nutrição. Para Vasconcelos ${ }^{22}$, na América Latina, a emergência da Nutrição decorre sob significativas contribuições dos estudos de Pedro Escudero, criador do Instituto Nacional de Nutrição em 1926, da Escola Nacional de Dietistas, em 1933, e do curso de médicos "dietólogos" da Universidade de Buenos Aires. Nestas experiências, diferentes brasileiros foram partícipes, dentre os quais se destacou o pernambucano Josué de Castro. De acordo com Vasconcelos ${ }^{23}$, Escudero, Josué de Castro e seus colaboradores constituíram os pioneiros na promoção de estudos e intervenções de nutrição no campo social no Brasil, com maior 
ênfase a partir da década de 1930, elaborando paulatinamente bases teóricas para se compreender questões alimentares e nutricionais, como a fome, de forma complexa e crítica.

Dessa maneira, em sua origem, a Nutrição Social estava atrelada às preocupações de médicos nutrólogos, particularmente com aspectos relacionados à produção, à distribuição e ao consumo de alimentos pela população brasileira. Sob as bases deste grupo, configuraram-se espaços fundamentais da constituição da Nutrição Social como campo significativo no contexto das práticas da recém-criada profissão do nutricionista ${ }^{24}$.

Nesse contexto, como afirma Boog ${ }^{25}$, a Nutrição Social esteve fortemente vinculada aos programas de proteção dos trabalhadores e expressou-se através de iniciativas de Educação Alimentar e Nutricional (EAN) concretizadas em perspectivas de transmissão de informações, difusão de boas práticas e visitas domiciliares visando o acompanhamento de hábitos e atitudes visando uma alimentação "correta".

No contexto da Saúde Pública, a Nutrição Social dedicou-se, inicialmente, aos sistemáticos estudos sobre o problema da fome, suas repercussões e determinantes sociais, bem como as questões nutricionais relativas. A partir da década de 1950 e durante a década de 1960, muitos profissionais enfatizam suas ações a partir de programas de ajuda alimentar em políticas de assistencialismo como aquelas provenientes do USAID ${ }^{(c)}$, onde se trazia alimentos estranhos à cultura brasileira, principalmente provindos dos Estados Unidos, de modo a inseri-los como doação em contextos de pobreza. Por sua vez, especialmente a partir dos anos 1970, a lógica desenvolvimentista e tecnicista governamental da Ditadura Militar influi no estabelecimento de ações de nutrição restritas à avaliação e diagnóstico alimentar e nutricional, bem como ao planejamento quanto às necessidades de abastecimento, produção e comercialização de alimentos, o que oportunizou o fortalecimento da perspectiva de Vigilância Alimentar e Nutricional, mas pouco afastou as possibilidades de trabalhar pedagogicamente e participativamente a questão alimentar e seus determinantes ${ }^{24}$. Para Boog ${ }^{25}$, neste período decorre um "exílio" da EAN.

A partir da década de 1980, a Nutrição Social respira novos ares graças a processos como os movimentos pela redemocratização, os movimentos e práticas populares de saúde, e a redescoberta do debate em torno da fome como questão social, atrelada a crescente discussão crítica em torno da Nutrição ${ }^{26}$. Nesse processo, a instituição do Sistema Único de Saúde (SUS) e seu fortalecimento através da criação e expansão do Programa Saúde da Família (atualmente compreendido como Estratégia Saúde da Família) na década de 1990 logrou êxito em demandar das políticas públicas de Alimentação e Nutrição trabalhos sociais com perspectivas diferenciadas daquelas consolidadas nas últimas décadas, especialmente no período pós-Josué de Castro.

Concomitantemente, o problema da fome no Brasil passou a ser cada vez mais compreendido como um fenômeno social, político, econômico e cultural, indo muito além da simples ausência de alimentos. Tal constatação demandou uma notável transformação na abordagem governamental a este problema, a partir do momento em que passaram a ser construídas novas perspectivas teóricas e outros conceitos orientadores de políticas e ações para o enfrentamento destas questões. Isto passou a ser vivenciado na prática com o advento do Governo Lula em 2003, no qual - dentre outras medidas - a criação do Ministério de Desenvolvimento Social e Combate a Fome e do Programa Fome Zero demarcaram uma decisão assertiva do Governo Federal no sentido de inaugurar novas abordagens para

(c) United States Agency for Internacional Development. 
a implementação de políticas públicas nesta área. Dentre elas, o conceito de Segurança Alimentar e Nutricional (SAN) se sobressai ${ }^{14}$, bem como o de Direito Humano a Alimentação Adequada e Saudável (DHAA). Com a Lei Orgânica de Segurança Alimentar e Nutricional (LOSAN), a SAN passou a ser entendida como fenômeno cujo enfrentamento não pode prescindir de caminhos como a intersetorialidade e o diálogo interdisciplinar. Assim, defini-se a SAN:

A realização do direito de todos ao acesso regular e permanente a alimentos de qualidade, em quantidade suficiente, sem comprometer o acesso a outras necessidades essenciais, tendo por base práticas alimentares promotoras de saúde, que respeitem a diversidade cultural e que sejam social, econômica e ambientalmente sustentáveis ${ }^{27}$.

Nessa perspectiva, hoje se compreende Nutrição Social através da ênfase nos aspectos social, cultural, religioso, econômico e político relativos à alimentação e como estes podem influenciar nutrição humana ${ }^{5,9,28}$. Nesta linha, são desenvolvidos projetos voltados para:

[...] o planejamento, implementação, monitoramento e avaliação de Políticas Públicas e Programas que compõe as estratégias de Segurança Alimentar e Nutricional, e a promoção da realização do Direito Humano à Alimentação Adequada (DHAA); A análise e a proposição de estratégias de implementação de ações de Alimentação e Nutrição em políticas, programas e serviços como, por exemplo, saúde, educação e assistência social; Ações de proposição, implementação e validação de estratégias e instrumentos de promoção da saúde e educação nutricional para diferentes grupos populacionais; além de informação, educação formal e continuada de profissionais de saúde ${ }^{29}$.

A Nutrição Social configura um difuso campo de estudos e realizações, nos quais se desvelam estratégias de trabalhar o campo da Alimentação e Nutrição em interface com o cotidiano da vida e os determinantes sociais de saúde nas coletividades.

\section{Educação Popular e Nutrição Social: avanços e lacunas}

Como destaca Boog ${ }^{25}$, historicamente as ações de Educação Alimentar e Nutricional pouco conseguiram auxiliar efetivamente o educador em nutrição a compreender em profundidade $o$ fenômeno com o qual está lidando - alimentação humana. Corroborando com a referida autora, enfatizamos que a abordagem pedagógica em Educação Alimentar e Nutricional sempre esteve mais próxima da instrução, voltada a técnicas e procedimentos, em lugar do envolvimento dinâmico e compreensivo com a teia complexa e multifacetada da cultura humana.

Nessa direção, buscando cumprir o objetivo principal deste ensaio, procederemos com a explicitação dos encontros e diálogos existentes entre Educação Popular e as reflexões teóricas e as políticas de Nutrição Social, visando identificar de avanços e lacunas neste debate, sistematizando então algumas considerações e sugestões de desafios, na perspectiva de pensarmos caminhos para processos educacionais emancipatórios no contexto das práticas atuais de Nutrição Social.

Para tanto, cumpre destacar que, considerando os limites deste ensaio, deveremos nos ater a políticas públicas, consensos, relatórios e documentos construídos somente nos últimos anos, especialmente a partir de 2003. Assim, reforçamos nossa intenção em compor mais uma provocação ao debate e ao aprofundamento do tema do que um esgotamento de todas as possibilidades de reflexão possíveis.

A Lei Orgânica de Segurança Alimentar e Nutricional ${ }^{27}$ não contém menções explíticas a Educação Popular, mas chama atenção não mencionar tampouco a Educação, ou mesmo as práticas educativas. Aproximam-se destas perspectivas somente citações a: a) a participação cidadã plena, através da realização destes direitos (SAN e DHAA) constituir um conjunto de condições necessárias e essenciais para que todos os seres humanos, de forma igualitária e sem nenhum tipo de discriminação, existam, desenvolvam suas capacidades e participem plenamente e dignamente da vida em sociedade; b) a importância da participação social na formulação, execução, acompanhamento, monitoramento e controle das políticas e dos planos de segurança alimentar e nutricional em todas as esferas do governo; e c) a inclusão, dentre os princípios da Lei, da preservação da autonomia e respeito à dignidade das pessoas ${ }^{30}$. 
No mesmo documento, destaca-se a inclusão da educação nutricional no contexto dos elementos da SAN nas políticas de reforma agrágria, mas restringindo a mesma a capacitação para práticas pessoais saudáveis, textualmente indicando "ações de Educação Alimentar e Nutricional com vistas à melhoria dos hábitos alimentares, dos padrões de higiene e do aproveitamento dos alimentos pelas famílias assentadas" 30 . Todavia, exceção se faz presente nas reflexões sobre a inserção da EAN no cenário escolar, onde se enfatiza o significado da mesma como elemento articulador de diferentes setores na mobilização de ações sociais e formativas, especialmente saúde e educação. Ressalta-se a presença de principios caros à Educação Popular, da seguinte forma:

[...] devem ser pautadas na perspectiva dos direitos humanos e da cidadania, sob valores éticos e de eqüidade, reforçando, assim, a autonomia social, política e econômica da população atendida. Para tal, é fundamental que haja participação social, transparência decisória e conhecimento, por parte da população, das ações desenvolvidas em todas as etapas do processo de planejamento ${ }^{30}$.

Ainda nessa direção, o documento ressalta ${ }^{30}$ que as ações de promoção de saúde e de uma alimentação saudável envolvem também o fortalecimento político dos diferentes grupos para que possam pressionar pela garantia de todos esses direitos: acesso ao alimento e a uma alimentação saudável, acesso à informação, à atenção em saúde, aos bens e serviços públicos essenciais ${ }^{31}$.

Ao apresentar um balanço da implementação das diretrizes da Política Nacional de Alimentação e Nutrição (PNAN) contextualizando as ações no cenário do Sistema Único de Saúde (SUS), Recine e Vasconcellos ${ }^{32}$ referem-se à perspectiva educativa indicando que apenas ações de educação em saúde não são suficientes para o alcance do impacto necessário na promoção da alimentação saudável, pois necessita-se de estratégias como o Guia alimentar da população brasileira, que sistematiza e demarca pontos regulatórios e elementares quanto aos horizontes onde se quer chegar na promoção da SAN e da alimentação saudável.

De arcordo com Oliveira ${ }^{33}$, a Educação Alimentar e Nutricional é prevista na Estratégia Fome Zero como ação estruturante, de tal sorte que a mesma configurou-se institucionalmente no Ministério do Desenvolvimento Social e Combate à Fome (MDS) tendo como perspectiva a promoção da segurança alimentar e nutricional. Dessa forma, a Coordenação responsável pelo desenvolvimento de ações educativas nesse Ministério promoveu importantes recomendações e estratégias como base para o desenvolvimento de ações educativas em Alimentação e Nutrição tanto para o governo como para a sociedade civil. Dentre essas recomendações, destaca-se a importância de que as ações educativas sejam desenvolvidas no sentido de promover a autonomia dos indivíduos, a interdisciplinaridade e a transdisciplinaridade, respeitando as culturas alimentares e valorizando a história alimentar e a diversidade regional, ao mesmo tempo em que reconheçam os saberes populares e fomentem a biodiversidade local.

Nos últimos anos, alguns marcos são representativos do avanço no debate sobre a dimensão educativa nas práticas da Nutrição Social. Um exemplo disto está na nova edição da PNAN - Política Nacional de Alimentação e Nutrição ${ }^{34}$. Dentre seus princípios, destacam-se elementos como: a Alimentação como elemento de humanização das práticas de saúde; o respeito à diversidade e à cultura alimentar; o fortalecimento da autonomia dos indivíduos; a determinação social e a natureza interdisciplinar e intersetorial da Alimentação e Nutrição; segurança alimentar e nutricional com soberania.

Em 2012, a criação do Marco de Referência de Educação Alimentar e Nutricional nas Políticas Públicas, coordenado pelo Ministério do Desenvolvimento Social e Combate à Fome (Secretaria Nacional de Segurança Alimentar e Nutricional), constituiu um avanço significativo na delimitação de caminhos para uma educação crítica no contexto das ações de SAN e DHAA. O Marco de Referência tem o objetivo de promover um campo comum de reflexão e orientação da prática, no conjunto de iniciativas de Educação Alimentar e Nutricional que tenham origem, principalmente, na ação pública, e que contemple os diversos setores vinculados ao processo de produção, distribuição, abastecimento e consumo de alimentos ${ }^{35}$. 
No que diz respeito à literatura e os principais estudos empreendidos no campo da Nutrição na perspectiva da Saúde Pública e da Segurança Alimentar e Nutricional, pode-se identificar diálogos com a Educação Popular, dentre os quais se destacam principalmente os trabalhos de Maria Cristina Faber Boog, a qual vem consolidando o campo da Educação Alimentar e Nutricional com sistematizações precisas, com caracterizações históricas do processo de constituição da EAN, e apontando desafios para esta prática. Neste quesito, a autora aponta uma educação crítica como caminho fundante. Numa de suas obras, a autora sugere que

[...] a leitura da extensa obra de Paulo Freire seja a referência básica para a formação dos educadores em nutrição. Ninguém como ele conseguiu tão bem discutir as possibilidades e os limites da educação formal e informal, a natureza da educação como ato político, as características e o potencial da dialogicidade para a construção da autonomia, a educação como caminho para a libertação das condições sociais de opressão, focalizando a educação como via para a transformação da situação concreta de existência a fim de que se possa desfrutar de uma vida digna, na qual se inclua, entre outras condições, a segurança alimentar e nutricional ${ }^{9}$.

Nessa perspectiva, vale destacar o protagonismo da obra de Boog no sentido de provocar o adensamento da reflexão crítica em torno das ações de Educação Alimentar e Nutricional, particularmente aquea que as conduzam em trilhas libertadoras. Conforme ressalta a autora, a atuação dos nutricionistas neste campo ainda é dominada

[...] pelo empirismo e por um certo idealismo que pode levar a um fazer que não se dá conta das intencionalidades subjacentes à abordagem empregada nas ações educativas. É preciso acordar para o fato de que o processo social da educação existe sempre, e que a recusa em fazê-lo sistematicamente, apenas abre um espaço maior para que ele aconteça de forma espontânea, ou, pior do que isso, intencional, porém através de iniciativas que partem exclusivamente das indústrias de alimentos, as quais, através da mídia e hoje, até mesmo das escolas, desenvolvem programas de "educação" nutricional25.

Influenciadas por estas perspectivas, ou com base em experiências exitosas, no debate atual em torno da Nutrição Social, vem se demarcando um discurso em torno da Educação Alimentar e Nutricional "transformadora" e dialógica, assumindo uma perspectiva "problematizadora", com vistas a ultrapassar uma visão puramente instrumental e instrucional da educação e passar a considerá-la como uma forma de realização da pessoa ${ }^{36}$. De acordo com a autora citada, percebe-se nos documentos, orientações e estabelecimentos oficiais uma clara intencionalidade de articular, do ponto de vista teórico-metodológico, a Educação Alimentar e Nutricional a uma perspectiva da educação cunhada no pensamento de Paulo Freire, com ênfase na dialogicidade e na autonomia do sujeito. Nesta direção, ainda mescla-se algumas contribuições da pedagogia construtivista. Assim, os discursos recorrem ao enfoque da problematização contrapondo aos métodos tradicionais baseados nas técnicas expositivas, a fim de promover uma prática reflexiva dos sujeitos sobre si e sobre as questões pertinentes às suas práticas alimentares.

Nessa direção, Conti ${ }^{37}$ defende que

[...] a existência de leis não significa que elas [as políticas públicas de SAN] estejam sendo efetivadas nos diferentes espaços. Por isso, ao mesmo tempo em que se avança no arcabouço legal é preciso continuar avançando no fortalecimento das organizações e movimentos sociais populares, que são instrumentos de mobilização e pressão política importantíssima pela realização e efetivação do DHAA, sem os quais esta efetivação tende a se tornar lenta, burocrática e enfocada, sem força de efetividade universal.

Por sua vez, Ferreira e Magalhães ${ }^{7}$ apontam a Educação Popular entre uma série de questões articuladas na proposta de Promoção da Saúde como um caminho promissor para o campo da Alimentação e Nutrição: “[...] capacitação dos indivíduos; parcerias nas ações; intersetorialidade 
de órgãos públicos e privados; reforço à ação comunitária; educação popular; cidadania; ética pública [...]". Seguindo esta direção, no âmbito das ações direcionadas à capacitação dos indivíduos, Ferreira e Magalhães ${ }^{7}$ destacam o propósito de garantir condições para que a população possa exercer sua autonomia decisória, optando por escolhas alimentares mais saudáveis. Nesse aspecto, a EAN assume um papel fundamental para o exercício e fortalecimento da cidadania alimentar. A prática do nutricionista assume o desafio de promover uma educação nutricional eficaz, com ações que promovam mudanças nos hábitos alimentares dos indivíduos e de suas famílias.

\section{Educação Popular e Nutrição Social: possibilidades e desafios}

Até aqui, buscamos traçar um breve painel sobre o contexto histórico de movimentos de encontro entre a perspectiva da Educação Popular e as ações de Nutrição Social, assim como também nos debruçamos sobre a presença de conceitos teóricos e dimensões políticas da Educação Popular em documentos oficiais e reflexões acadêmicas sobre a Nutrição num conceito ampliado no cenário da Promoção da Saúde.

Diante do exposto, podemos delinear algumas considerações, as quais se configuram muito mais como reflexões teóricas e desafios revelados como convites para a continuidade e o aprofundamento deste debate.

Em primeiro lugar, cumpre destacar que a ausência preponderante de aprofundamentos sobre a dimensão educativa da Nutrição Social nos documentos e políticas públicas oficiais pesquisados demonstra a ausência de centralidade no debate sobre a Educação Alimentar e Nutricional neste âmbito, e revela uma falta de sincronicidade entre os propósitos transformadores expressos nestas políticas (como a SAN e o DHAA) e a educação como um caminho capaz de contribuir para sua efetividade. Ao contrário do que possa parecer, isso não se deve a uma falta de experiências educativas neste campo. O que se torna fundamental, então, é expandir e aprofundar a capacidade de sistematizar as experiências de Educação Alimentar e Nutricional em SAN e DHAA, bem como qualificar a interlocução do apoio dos agentes públicos a estas realizações.

Nessa direção, chama atenção também a timidez deste debate no campo acadêmico. É necessário dar continuidade e aprofundamento às bases teóricas fundamentais semeadas por Boog desde a década de 1990 até os dias de hoje.

Não obstante, cumpre destacar que será pouco empreender apenas reflexões sobre a Educação Alimentar e Nutricional como um todo. O contexto atual de exclusão social e permanente de modelos de desenvolvimento excludentes recomendam ser necessário pensar a Nutrição Social com processos educacionais fundamentalmente emancipatórios. A falta de estudos capazes de associar este campo ao da Educação Popular, de maneira explítica, evidencia o quanto a discussão em torno de uma Educação Alimentar e Nutricional persiste em segundo plano.

Não que avaliemos ser a Educação Popular a única saída crítica ao quadro sombrio que campeia o contexto social atual. Como afirmamos anteriormente, há outras perspectivas educacionais articuladas ao Campo Democrático Popular. Contudo, a permanente expansão e fortalecimento de experiências de Educação Popular em Saúde coloca esta vertente como uma das mais centrais no cenário atual de elaboração de iniciativas e reflexões educativas no campo social. Haja vista, inclusive, o recente processo de institucionalização desta perspectiva nas políticas públicas de saúde com a Política Nacional de Educação Popular em Saúde ${ }^{(\mathrm{d}), 4}$.

\footnotetext{
(d) Aprovada pelo Conselho Nacional de Saúde em 2012 e coordenada, em seu processo de criação e desenvolvimento, pelo Comitê Nacional de Educação Popular em Saúde da Secretaria de Gestão Estratégica e Participativa do Ministério da Saúde.
} 
A teoria da Educação inspirada pela Educação Popular, conforme sistematizada por Paulo Freire ${ }^{11}$, ensina que as questões éticas, filosóficas e metodológicas concernentes à Educação Popular não se reservam apenas à análise das práticas, ações ou momentos educativos, mas transbordam estes na perspectiva de gerar olhares, críticas e novos direcionamentos para o conjunto das ações, para a perspectiva da ciencia, para sua relação com a sociedade, para seu papel, seu compromisso. Nesse sentido, corroborando com a perspectiva teórica fundamentada por Pinto ${ }^{38}$ :

A ciência só pode tornar-se um instrumento de libertação do homem e do mundo nacional se for compreendida por uma teoria filosófica que a explique como atividade do ser humano pensante e revele o pleno significado da atitude de indagação em face da realidade natural e social.

Na perspectiva da Educação Popular, não basta pensar as dimensões educativas nos momentos de relação entre científico e popular ou nos momentos de capacitação ou na ação comunitária, mas o que há de educativo e político em todas as dimensões de análise da Nutrição Social. Aprofundando esta reflexão, na esteira da obra de Pinto $^{38}$, a Educação pode constituir um elemento potencializador da capacidade de questionamento da ciência e do homem diante do mundo e sua realidade. Como ressalta este autor, "para quem trabalha e para produzir o quê, ou seja, está ele a serviço dos propósitos humanos ou como instrumento de alienação do homem?".

Em nossa análise, percebemos ainda persistir um obstáculo significativo para se alcançar este horizonte, o qual, na acepção de Santos ${ }^{36}$, consiste na existência de um hiato entre as formulações das políticas e as ações desenvolvidas no âmbito local. Para a autora, permanece certa distância entre discursos e práticas em torno das ações educativas. Conclui que a Educação Alimentar e Nutricional é menos um instrumento do que um dispositivo de ações conjugadas que devem envolver diferentes setores e disciplinas, entretanto, demanda investimentos na formação profissional e na produção de conhecimento no campo.

Destacamos, assim, que uma contribuição fundante no diálogo entre Educação Popular e Nutrição Social consistiria em aprimorar a Educação Alimentar e Nutricional numa prática fundamentalmente popular, na acepção sistematizada por Melo Neto ${ }^{12}$. Para o autor, ser popular é tornar-se expressão de uma metodologia, mas só terá significado quando expressar uma visão de mundo em mudança, contendo em suas ações a dimensão de propor saídas para as situações de miséria vividas pelo povo. Assim, expressa jeitos de fazer e iniciativas definidoras de um novo tecido social embasado em outros valores e objetivos. A metodologia que confirma algo como popular tem o sentido de promover o diálogo entre os partícipes das ações. Sobretudo, deve ser contributiva ao processo de se exercer a cidadania crítica.

De acordo com Melo Neto ${ }^{12}$, outra dimensão do popular se expressa quando a ação tem origem nos esforços, no trabalho do povo, das maiorias (classes), dos que vivem e viverão do trabalho. Mas a origem apenas não basta. Ser popular é ter clareza de que há um papel político nessa definição. Essa dimensão política deve estar voltada à defesa dos interesses das maiorias, ou seja, as classes populares. Nesse sentido, para o referido autor:

Ser popular é tentar alternativas. É estar realizando o possível, mas que, ao se realizar, abre, contraditoriamente, novas possibilidades de utopias, cuja negação trará os elementos já efetivados e tentativas de novas realizações. Isto só ocorre, contudo, quando da sua realização mesma, caminhando para aquilo que, efetivamente, é o necessário. A utopia da democracia tem um valor permanente e deve ser vivida sem qualquer entrave. Precisamente, nos espaços da realização e da não-realização, estão as suas contradições e suas dificuldades maiores. Entretanto, não podem trans-formar-se em agentes impeditivos da intransigente e radical busca por novas concretizações de sonhos de liberdade e de felicidade ${ }^{12}$.

Nesse sentido, embora haja uma preocupação crescente em relação às bases teórico-metodológicas que regem as ações educativas em Nutrição Social, há ainda pouca explicitação teórica e elaboração metodológica sobre a educação como um elemento potencializador da conscientização e formação 
necessária para a atuação cidadã na perspectiva da autonomia, da participação e da emancipação humana em Nutrição Social ${ }^{36}$. Muitos documentos enfatizam onde se quer chegar, mas são timidos em acreditar na educação como caminho, ou mesmo como elemento gerador de reflexões, saberes e práticas que remem neste sentido.

\section{Algumas considerações}

Muitos autores e obras têm avançado no sentido de delinear possibilidades educativas capazes de concretizar as intenções expressas nos conceitos de SAN e no marco do DHAA. Contudo, avaliamos ser necessário, no atual contexto de exclusão social, dedicar mais estudos e reflexões críticas na perspectiva da promoção de processos emancipatórios nas iniciativas de Educação Alimentar e Nutricional, o que deverá corroborar não apenas para novos horizontes para a ação do nutricionista, ou mesmo na melhoria do estado de SAN das comunidades, mas para a ressignificação efetiva da Nutrição Social.

Acreditamos que a Nutrição Social precisa caminhar no sentido de refletir intensamente sobre seu compromisso social e seu significado no enfrentamento obstinado e cotidiano das condições objetivas de opressão, injustiça e desumanização às quais está exposta parte significativa da população brasileira.

Com o presente ensaio, esperamos ter mantido aceso o debate em torno dos esforços sinceros e fundamentais que muitos autores já vêm mantendo no aprimoramento de possibilidades para a Educação Alimentar e Nutricional. Apresentamos, por outro lado, a possibilidade de interlocução da Educação Popular com a Nutrição Social como constituinte fundamental da efetivação de práticas transformadoras da Educação Alimentar e Nutricional. Com isso, avaliamos como premente a necessidade de se evidenciar explicitamente o caráter popular da prática educativa em Alimentação e Nutrição no sentido de revelar as dimensões multifacetadas da Nutrição Social e as possibilidades de se vislumbrar, mesmo que em exercícios e lances, uma Educação Alimentar e Nutricional emancipatória, encharcada de categorias como: diálogo, criticidade, participação, amorosidade e compromisso social popular.

\section{Referências}

1. Recine E, Gomes RCF, Fagundes AA, Pinheiro ARO, Teixeira BA, Susa JS et al. A formação em saúde pública nos cursos de graduação de nutrição no Brasil. Rev Nutr. 2012;25(1):21-33. http://dx.doi.org/10.1590/S1415-52732012000100003

2. Boog MCF. Atuação do nutricionista em saúde pública na promoção da alimentação saudável. Ciênc Saúde. 2008;1(1):33-42.

3. Motta DG, Oliveira MRM, Boog MCF. A formação universitária em nutrição. ProPosições (Campinas). 2003;14(1):69-86.

4. Burlandy L. Atuação do nutricionista em saúde coletiva. [S.I., s.n.].; 2005. [Mimeografado]

5. Santos AC. A inserção do nutricionista na estratégia da saúde da família: o olhar de diferentes trabalhadores da saúde. Fam Saúde Desenv. 2005;7(3):257-65.

6. Assis AMO, Santos SMC, Freitas MCS, Santos JM, Silva MCM. O Programa Saúde da Família: contribuições para uma reflexão sobre a inserção do nutricionista na equipe multidisciplinar. Rev Nutr. 2002;15(3):255-66. http://dx.doi.org/10.1590/S1415-52732002000300001

7. Ferreira VA, Magalhães R. Nutrição e promoção da saúde: perspectivas atuais. Cad Saúde Pública. 2007;23(7):1674-681. http://dx.doi.org/10.1590/S0102-311X2007000700019

8. Cervato-Mancuso AM, Tonacio LV, Silva ER, Vieira VL. A atuação do nutricionista na Atenção Básica à Saúde em um grande centro urbano. Ciênc Saúde Coletiva. 2012;17(12):3289-300. http://dx.doi.org/10.1590/S1413-81232012001200014 
9. Boog MCF. Contribuições da educação nutricional à construção da segurança alimentar. Saúde Rev. 2004;6(13):17-23.

10. Cruz PJSC, Pereira IDF, Vasconcelos ACCP. Educação popular e a promoção da segurança alimentar e nutricional em comunidades: desafios com base em uma experiência de extensão. In: Vasconcelos EM, Cruz PJSC, organizadores. Educação popular na formação universitária: reflexões com base em uma experiência. São Paulo: Hucitec; 2011.

11. Freire P. Pedagogia do oprimido. Rio de Janeiro: Paz e Terra; 2005.

12. Melo Neto JF. Extensão universitária: autogestão e educação popular. João Pessoa: Editora UFPB; 2004.

13. Gadotti M, Torres CA. Educação popular: utopia latino-americana. São Paulo: Cortez; 1994.

14. Vasconcelos ACCP, Pereira IDF, Cruz PJSC. Práticas educativas em nutrição na atenção básica em saúde: reflexões a partir de uma experiência de extensão popular em João Pessoa-Paraíba. Rev APS. 2008;11(3):334-40.

15. Minayo MCS. O desafio do conhecimento: pesquisa qualitativa em saúde. 11a ed. São Paulo: Hucitec; 2008.

16. Gil AC. Como elaborar projetos de pesquisa. 4a ed. São Paulo: Atlas; 2002.

17. Lander E. Marxismo, eurocentrismo, colonialismo. In: Borón A, Amadeo J, González S, organizadores. La teoría marxista hoy. Problemas y perspectivas. Buenos Aires: CLACSO; 2006.

18. Marx K, Engels F. A ideologia alemã. 10a ed. São Paulo: Hucitec; 1996.

19. Brandão CR. A Educação Popular na escola cidadã. Petrópolis: Vozes; 2002.

20. Calado AJFC. Educação popular como processo humanizador: quais protagonistas? In: Lins LT, Oliveira VLB, organizadores. Educação popular e movimentos sociais: aspectos multidimensionais na construção do saber. João Pessoa: Editora Universitária/UFPB; 2008.

21. Paludo C. Educação Popular em busca de alternativas: uma leitura desde o campo democrático popular. Porto Alegre: Tomo Editorial; 2001.

22. Vasconcelos FAG. O nutricionista no Brasil: uma análise histórica. Rev Nutr. 2002;15(2):127-38. http://dx.doi.org/10.1590/S1415-52732002000200001

23. Vasconcelos FAG. Josué de Castro e a Geografia da Fome no Brasil. Cad Saúde Pública. 2008;24(11):2710-7. http://dx.doi.org/10.1590/S0102-311X2008001100027

24. Vasconcelos FAG, Batista Filho $M$. História do campo da Alimentação e Nutrição em Saúde Coletiva no Brasil. Ciênc Saúde Coletiva. 2011;16(1):81-90. http://dx.doi. org/10.1590/S1413-81232011000100012

25. Boog MCF. Educação nutricional: passado, presente, futuro. Rev Nutr. 1997;10(1):5-19.

26. Valente FL. Fome e desnutrição: determinantes sociais. São Paulo: Cortez; 1986.

27. Brasil. Lei $n^{0} 11.346$, de 15 de setembro de 2006. Cria o Sistema Nacional de Segurança Alimentar e Nutricional - SISAN com vistas em assegurar o direito humano à alimentação adequada e dá outras providências. Diário Oficial da União. 18 set. 2006.

28. Vasconcelos FAG. A ciência da nutrição em trânsito: da nutrição e dietética à nutrigenômica. Rev Nutr. 2010;23(6):935-45. http://dx.doi.org/10.1590/S141552732010000600001

29. Universidade de Brasília. Faculdade de Ciências da Saúde. Departamento de Nutrição. Nutrição social. 2010 [acesso em 27 maio 2013]. Disponível em: http://fs.unb.br/ nutricaohumana/index.php?option =com_content $\&$ view $=$ article \&id $=49 \&$ Itemid $=55$. Acessado em 27 mai 2013.

30. Conselho Nacional de Segurança Alimentar e Nutricional. Princípios e diretrizes de uma Política de SAN. Brasília, DF: Positiva; 2004. 
31. Associação Brasileira pela Nutrição e Direitos Humanos. Direito humano à alimentação adequada no contexto da segurança alimentar e nutricional. Brasília, DF: Associação Brasileira pela Nutrição e Direitos Humanos; 2010.

32. Recine $E$, Vasconcellos $A B$. Políticas nacionais e o campo da Alimentação e Nutrição em Saúde Coletiva: cenário atual. Ciênc Saúde Coletiva. 2011;16(1):73-9. http://dx.doi. org/10.1590/S1413-81232011000100011

33. Oliveira SI, Oliveira KS. Novas perspectivas em educação alimentar e nutricional. Psicol USP. 2008;19(4):495-504. http://dx.doi.org/10.1590/S0103-65642008000400008

34. Ministério da Saúde (BR). Secretaria de Atenção à Saúde. Departamento de Atenção Básica. Política Nacional de Alimentação e Nutrição. Brasília, DF: Ministério da Saúde; 2012.

35. Ministério do Desenvolvimento Social e Combate à Fome. Marco de referência de educação alimentar e nutricional para as políticas públicas. Brasília, DF: Ministério do Desenvolvimento Social e Combate à Fome; 2012.

36. Santos LAS. O fazer educação alimentar e nutricional: algumas contribuições para reflexão. Ciênc Saúde Coletiva. 2012;17(2):453-62. http://dx.doi.org/10.1590/S141381232012000200029

37. Conti IL. Segurança alimentar e nutricional: noções básicas. Passo Fundo: IFIBE; 2009.

38. Pinto AV. Ciência e existência: problemas filosóficos da pesquisa científica. 2a ed. Rio de Janeiro: Editora Paz e Terra; 1979.

39. Pádua JG, Boog MCF. Avaliação da inserção do nutricionista na Rede Básica de Saúde dos municípios da Região Metropolitana de Campinas. Rev Nutrição. 2006;19(4):413-24. http://dx.doi.org/10.1590/S1415-52732006000400001

40. Amorim STP, Moreira H, Carraro TE. A formação de pediatras e nutricionistas: a dimensão humana. Rev Nutrição. 2001;14(2):111-8. http://dx.doi.org/10.1590/S141552732001000200004

Cruz PJSC, Melo Neto JF. Educación popular y nutrición social: consideraciones teóricas sobre un diálogo posible. Interface (Botucatu). 2014;18 Supl 2:1365-1376.

En el sector de la salud, la Educación Popular ha dado a conocer perspectivas teóricas y metodológicas históricamente relevantes en la búsqueda de nuevos horizontes para la educación de profesionales, entre los que se incluyen también nutricionistas. Los caminos han sido diseñados para un rendimiento comprometido con conceptos de Promoción de la Salud, Seguridad Alimentaria y Nutrición, que se suman a las dimensiones críticas de Nutrición Social, traducido por una percepción comprometida acerca de nutrición en comunidades populares. Con el objetivo de contribuir con la mejoría de los fundamentos teóricos que intervienen en este proceso, el presente ensayo tiene como objetivo sistematizar desafíos actuales, posibilidades y limitaciones de encuentro entre Educación Popular y Nutrición Social con énfasis en sus logros en los escenarios de la salud de la familia, y los movimientos por el Derecho Humano a la Alimentación Adecuada y Saludable en Brasil.

Palabras clave: Educación en Salud. Programas y Políticas de Nutrición y Alimentación. Nutrición en Salud Pública. Educación Alimentaria y Nutricional. 